\title{
Orientação: um tesouro pedagógico das práticas corporais de aventura
}

\author{
Orienteering: a pedagogical treasure for adventure body practices
}

\section{Denise Correa Luz, Amauri Aparecido Bássoli Oliveira}

Universidade Estadual de Maringá (UEM), Maringá, Brasil

\author{
HISTÓRICO DO ARTIGO \\ Recebido: 28 maio 2021 \\ Revisado: 20 agosto 2021 \\ Aprovado: 01 setembro 2021
}

\section{PALAVRAS-CHAVE:}

Orientação; Práticas Corporais de

Aventura; Ensino Fundamental

Educação Física.

\section{KEYWORDS:}

Orienteering; Adventure Body Practices; Elementary School; Physical Education.

\section{RESUMO}

INTRODUÇÃO: O incentivo à prática da Orientação, no ambiente escolar possibilita aos estudantes: compreender, produzir, vivenciar e relacionar conhecimentos entrelaçado entre manifestações sociais e cultura corporal. As práticas corporais de aventura (PCAs) alcançam novos adeptos e têm sido reconhecidas pela sociedade que busca da (re)aproximação com a natureza e fuga de ambientes urbanos. Ao professor de educação física cabe o desafio de contextualizar e ofertá-las possibilitando os estudantes reflexões e vivências de movimento.

OBJETIVO: O objetivo dessa proposta pedagógica, neste relato de experiência foi apresentar a Orientação e suas possibilidades no ambiente escolar, estimulando as PCAs com diversão, e potencial desenvolvimento cognitivo, funcional, social e pessoal.

MÉTODO: A proposta foi realizada com 30 (trinta) estudantes matriculados em uma turma de 50 (quinto) ano, do ensino fundamental I, com idades entre 10 e 11 anos de uma escola pública em Curitiba/PR. Diversos materiais lúdicos e pedagógicos foram disponibilizados e confeccionados com e para os estudantes. Conversas sobre a história da Orientação, os equipamentos utilizados, a leitura de mapas, cores e símbolos foram abordadas. Como ampliação de conhecimento os estudantes participaram de uma atividade surpresa, na qual puderam realizar uma pista sprint dentro da unidade escolar, com mapa produzido exclusivamente para o dia. RESULTADOS: Percebemos que houve ótima aceitação dos estudantes em todo o processo, observando o ambiente escolar com maiores possibilidades de conhecimentos, tais como atitudes de preservação da natureza, resolução de situações problemas em ambiente conhecido e seguro, protagonismo estudantil e relação com o outro.

CONCLUSÃO: Conclui-se que a Orientação é um conteúdo rico e uma prática segura no ambiente escolar, pois promove experimentações e noções espacial e temporal, estimula a criatividade, a iniciativa e superação de limites. É um conteúdo que pode ser contemplado na estrutura curricular das aulas de Educação Física, tendo em vista toda a sua potencialidade formativa.

\section{ABSTRACT}

BACKGROUND: The incentive to practice orienteering in the school environment allows the student to understand, produce, experience and relate knowledge intertwined with social manifestations and body culture. The adventure body practices reach new followers and they have been recognized by the society that searches for reconnection with nature and looks for an escape from urban environments. The physical education teacher has the challenge of contextualizing and offering those practices, enabling students to reflect and experience movement sabed on from their own experiences in class.

OBJECTIVE: The objective of this pedagogical proposal, presented in this experience report, in five classes, was to present the orienteering and its possibilities of practices in the school environment, stimulating physical activity practices with fun, and potential cognitive, functional, social and personal development.

METHODS: The proposal was carried out with 30 (thirty) students enrolled in a 5th grade class, from elementary school I, aged between 10 and 11 years old from a public school in Curitiba city. When the practice was offered to students, several playful and educational objects were made available in order to provide protagonism. Conversations about the sport's history, the equipment used, the reading of maps, colors and symbols, and types of sports were held, were discussed. As an expansion of knowledge, students participated in a surprise activity, in which they were able to run a sprint track inside the school, with a map produced exclusively for the day.

RESULTS: We noticed that there was a great acceptance by students throughout the process, observing the school environment with greater possibilities of knowledge, such as attitudes of nature preservation, problem solving in a known and safety environment, protagonism and relationship with others.

CONCLUSION: It is concluded that the orienteering is a pedagogically rich content and a safe practice in the school environment, as it promotes exploration and spatial and temporal notions, stimulates creativity, as well as initiative and overcoming limits. It is a content that needs to be included in the curriculum structure of Physical Education classes, in view of all its formative potential. 


\section{INTRODUÇÃO}

A dinâmica da Educação Física Escolar (EFE), que é o componente curricular que tematiza as práticas corporais, deve oferecer diversas formas de manifestações expressivas por meio de ações pedagógicas que atualizem, ampliem, ressignifiquem, valorizem e transformem os conteúdos da área, os quais estão diretamente conectados ao corpo, a cultura e o movimento (DAOLIO, 2007; FRANCO; CAVASINI; DARIDO, 2017; BRASIL, 2018; CURITIBA, 2020).

A Base Nacional Comum Curricular (BNCC) ressalta que as práticas corporais devem ser abordadas como fenômeno cultural dinâmico, diversificado, pluridimensional, singular e contraditório, pois podem assegurar aos estudantes um conjunto de saberes que permitam ampliar sua consciência a respeito de seu repertório motor, dos recursos para o cuidado de si e dos outros e desenvolver autonomia para apropriação e utilização da cultura corporal de movimento (BRASIL, 2018).

Reconhecemos haver muitos profissionais inovando e recriando suas práticas, apesar de historicamente a EFE empenhar-se em superar o senso comum e desmistificar as formas já enraizadas das diversas práticas e manifestações corporais descompromissadas na escola (DAOLIO, 2007; CÁSSARO, 2019). Ao docente, professor de Educação Física, cabe buscar constantemente meios de atualização profissional, reflexão contínua e (re)construção de sua prática e saberes (SOUZA; ARAÚJO; SANTOS, 2016; SILVA, 2020). Para atingir qualidade e especificidade no ensino da Educação Física, deve-se considerar práticas significativas e a possibilidade de expandir a cultura corporal dos estudantes (CURITIBA, 2020).

É de responsabilidade do professor de Educação Física propor novas vivências corporais aos estudantes, apresentando a eles oportunidades de um se movimentar que vai além de um ensino que prioriza gestos técnicos e táticos. Concomitantemente a isso, precisa trabalhar esse componente curricular na perspectiva reflexiva, viabilizando a formação de estudantes autônomos, articulados, capazes de compreender, produzir e relacionar conhecimentos entrelaçados às manifestações corporais, compreendendo-as como uma práxis social, por meio da qual atuará no mundo, ampliando as relações sociais (RODRIGUES; DARIDO, 2008; CURITIBA, 2020).

A BNCC ao contemplar as Práticas Corporais de Aventura (PCA) como unidade temática do componente curricular Educação Física, dá início a um desafio e proposta de disseminação de uma manifestação corporal com forte potencial pedagógico (INÁCIO et al., 2016; SOUZA; ARAÚJO; SANTOS, 2016). Assim, as PCAs em surgimento alcançam novos adeptos, esportistas ou não, a cada nova modalidade que surge, que buscam uma (re) aproximação com a natureza, satisfação pessoal e a fuga dos ambientes urbanos/cotidianos.

A BNCC recomenda que a Educação Física enquanto componente curricular proporcione (aos estudantes), experiências para além de seu cotidiano, oportunizando formas de ação e interação para uma vida em sociedade (INÁCIO et al., 2016), "não como fim, mas como meio para uma compreensão mais aprofundada dos modos que se expressa e de participar do mundo" (BRASIL, 2018, p. 64). O documento ressalta ainda que as PCA devem ser adaptadas às condições da escola, tomando-se como referência o cenário de cada contexto escolar (BRASIL, 2018). As
PCA assim expressam movimentos privilegiados por estarem de acordo com a realidade local e hábitos contemporâneos sociais, corporais e esportivos (CORRÊA et al., 2020).

Na Rede Municipal de Ensino de Curitiba as PCA estão presentes no Currículo da Educação Física nos anos finais do Ensino Fundamental, e podem estar presentes nos anos iniciais quando o professor assume interesse em transmitir essa prática atrelada aos demais conteúdos inseridos no Currículo. Sugere-se a necessidade de suscitar o acesso a vivências vinculadas à ampla compreensão de particularidades de cada modalidade, considerando a participação ativa dos estudantes dentro e fora da escola (CURITIBA, 2020).

A Orientação (também conhecida como Corrida de Orientação ou Esporte Orientação) é uma das práticas corporais encon-tradas na unidade temática PCA, sugeridas pela BNCC. Iremos assumir neste relato o termo Orientação devido ao entendimento de aqui diferenciá-la de uma modalidade esportiva tradicional, com base no ambiente que ela pode acontecer sendo preferenci-almente na natureza, onde o praticante interage com o meio, sem destacar preocupações com técnicas ou táticas de execução, característico de uma PCA.

A Orientação oportuniza oportuniza a vivência e a exploração do ambiente. A sua realização se dá com poucos e possíveis materiais, dentro e fora da escola, vindo ao encontro das atuais tendências sociais de bem-estar, saúde, performance, contato com a natureza, preservação, dentre outros (CARVALHO, 2020, p. 11). O objetivo da prática é que os participantes percorram, num menor tempo possível, uma distância estipulada de um percurso desconhecido, marcado por postos de controle pré-determinados e identificados num mapa do terreno (ou croqui), utilizando uma bússola, no caso das categorias experientes. Esta modalidade exige de seus praticantes certas habilidades, como a leitura precisa dos mapas, avaliação e tomada de decisões rápidas para a escolha da rota, concentração sob tensão, correr em terreno natural entre outras (CARVALHO, 2020; IOF, 2020).

Consequentemente, podemos identificar outros fatores importantes na prática da Orientação como envolvimento social, estar ao ar livre, evitar ambientes e hábitos insalubres, melhorar o humor, encorajar tomada de decisões, desenvolver autoconfiança, superar limites corporais, melhorar condicionamento aeróbio, ser ágil e saber competir. Um "círculo vicioso" entre PCA - Promoção da Saúde - Inclusão - Aumento do Lazer - PCA, no qual a prática de atividade Física irá gerar menos tempo sedentário e aumento dos benefícios à saúde ao longo da vida (SCOPEL et al., 2020).

Cabe aos professores de Educação Física, por meio das PCA, durante as aulas EFE, promoverem atitudes saudáveis e ecológicas para ajudar na construção de um cidadão de forma integral (CARVALHO, 2020, p. 11). Oportunizar a prática reflexiva da Orientação no ambiente escolar pode ser uma experiência objetiva nas ações de protagonismo dos estudantes.

Finalmente, apesar de a BNCC incluir as PCA em seu conteúdo oficial, ainda poucos professores aplicam as práticas, seja pelo desconhecimento ou restrição de espaço escolar e/ou materiais. O objetivo dessa proposta pedagógica foi apresentar a Orientação e suas possibilidades no ambiente escolar, estimulando práticas de atividade física com diversão e potencial de estímulo cognitivo, funcional, social e pessoal, o qual trazemos aqui como um relato de experiência. O intuito foi ampliar os co- 
nhecimentos dos estudantes sobre PCA de forma lúdica, construindo saberes sobre particularidades desta prática, à aventura, à conservação e preservação do meio ambiente nas aulas de Educação Física.

\section{MÉTODOS}

\section{Organização e desenvolvimento da proposta}

Essa sequência pedagógica foi realizada no segundo semestre de 2019, na Escola Municipal Eny Caldeira, na cidade de Curitiba, Paraná, que possui turmas da Educação Infantil e Ensino Fundamental (anos iniciais). O conteúdo PCA: Orientação, foi aplicado a uma turma de estudantes matriculados no 50 ano, no período da manhã, totalizando 27 estudantes, com faixa etária de 10 a 11 anos de idade.

A pesquisadora encontrava os estudantes de quinze em quinze dias, metade da turma a cada quinzena. Dividindo assim a turma com professora de Educação Física referência no horário escolar, sendo essa proposta um projeto escolar. Isto é, a professora de Educação Física da turma (LFN) ficava com uma média de 15 (quinze) estudantes, trazendo seu conteúdo programado seguindo o currículo municipal e a pesquisadora (DCL) com os outros estudantes nesta vivência da Orientação; na semana seguinte invertiam-se os grupos, repetindo as atividades para que toda a turma fosse contemplada.

A metodologia foi aplicada em sala de aula e espaço escolar, dividida em cinco momentos:

AULA 1: a professora apresentou aos estudantes o que é a Orientação, em uma conversa em sala de aula com apresentação de vídeo ${ }^{1}$ e imagens sobre a prática (Figura 1), e foram levantadas informações e curiosidades, onde os estudantes puderam fazer questionamentos sobre a prática e se familiarizarem com o tema. Na sequência a professora esclareceu sobre a importância de cores e símbolos utilizados em um mapa de Orientação, informando que a prática pode ser feita em ambientes urbano e/ou floresta. Nesta aula a avaliação se deu de forma diagnóstica e observacional, onde a professora considerou o envolvimento dos estudantes com o tema, se participaram da conversa e se expuseram suas impressões.

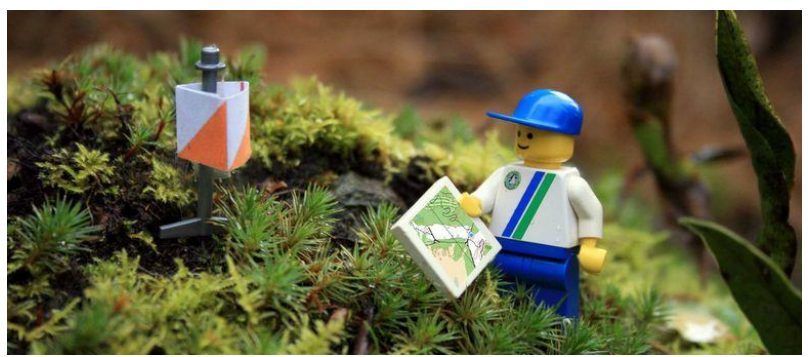

Figura 1. Lego Orientação: para ilustrar uma prática de Orientação na floresta, com prisma marcando o ponto de controle e o mapa sendo utilizando pelo praticante.

Fonte: http://www.stpaulinuscps.org.uk/orienteering/

AULA 2: os estudantes foram levados ao pátio da escola para realizarem dois jogos de montagem, através de uma estafeta: um referente a cores e formas, no qual deveriam montar os desenhos,

canal no YouTube: Orientista em Foco trás diversos vídeos que ensinam o aprendizado da Orientação para iniciantes até avançados. Escolhemos neste dia: https://youtu.be/NSMOyk5pOOI - Sobre Corrida de Orientação, Mapas e Rotas. encaixando exatamente as formas e cores ${ }^{2}$, o outro jogo proposto, em grupos, os estudantes deveriam montar um quebra-cabeças da Orientação, substituindo o mapa de uma casa e jardim, por formas e símbolos de um mapa de orientação (Figura 2). A avaliação foi feita por meio de observação das atitudes dos estudantes na compreensão das sobreposições das imagens e alegria ao executar a prática, contribuindo cada um com seu grupo, demonstrando ótimo trabalho em equipe. Alguns estudantes se destacaram como líderes do grupo na montagem do quebra-cabeças.
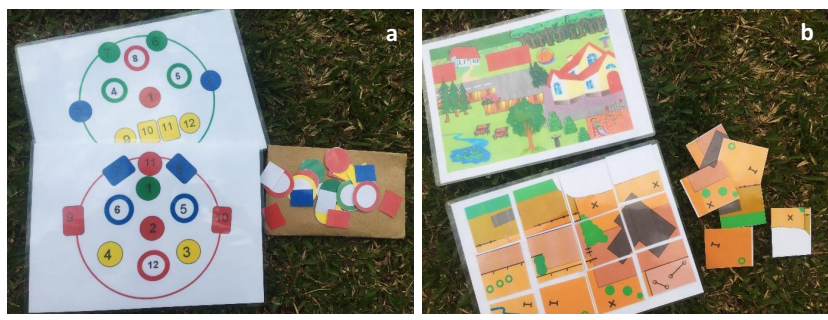

Figura 2: a. Encaixes geométricos; b. Quebra-cabeça da Orientação.

Fonte: Os autores.

AULA 3: em sala de aula, a professora apresentou vídeos sobre os equipamentos utilizados na Orientação e falou sobre a questão da segurança na sua prática, bem como níveis de conhecimento e classificação dos praticantes por idade em competições. Cada estudante aprendeu sua classificação em uma competição, como exemplo: DN10 (Damas Novato 10 anos). A avaliação se deu através da compreensão dos temas realizados nesta aula, as discussões e escrita sobre classificação por idade.

AULA 4: os estudantes puderam conhecer e praticar jogos de forma lúdica, ampliando conhecimento sobre a simbologia dos mapas. Diversas figuras representando informações de um mapa foram colados pela escola e os estudantes de pose de vários nomes deveriam encontrá-las e combinar: nomes e símbolos (ver exemplos Figura 3). Ao final da aula por meio de roda de conversa a professora mediou reflexões sobre o aprendizado e a experiência do dia, destacando as proporções que devem ser feitas em mapas em relação aos objetos e ambiente.

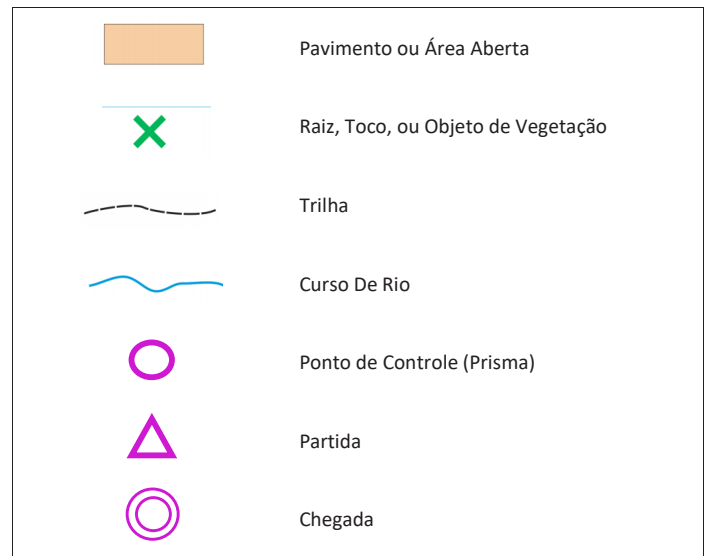

Figura 3. Símbolos e cores que podem ser encontrados em um mapa de Orientação. Fonte: Os autores.

Jogo disponivel para download em: https://www.britishorienteering.org.uk/images/uploaded/ ownloads/schools t 
AULA 5: na parte final da sequência pedagógica, os estudantes foram levados para a quadra poliesportiva da escola e foi proposta uma prática muito próxima a uma competição de Orientação na modalidade Sprint em ambiente urbano. A professora preparou os mapas com antecedência (ver Figura 4), colocou os prismas de papelão e picotadores nos pontos de controle, entregou para cada criança um mapa da escola e um cartão controle, explicou toda a dinâmica de perfuração do cartão controle e permitiu que os estudantes saíssem à "caça" dos pontos de controle aleatoriamente, utilizando o mapa e fizessem o percurso o quanto antes. Ao final da aula foi realizada uma roda de conversa para refletirem sobre os aprendizados da vivência realizada, os desafios desta prática, as possibilidades de realizá-la em ambientes urbanos e florestas, além de conversar sobre as curiosidades dos estudantes sobre os símbolos encontrados no mapa.

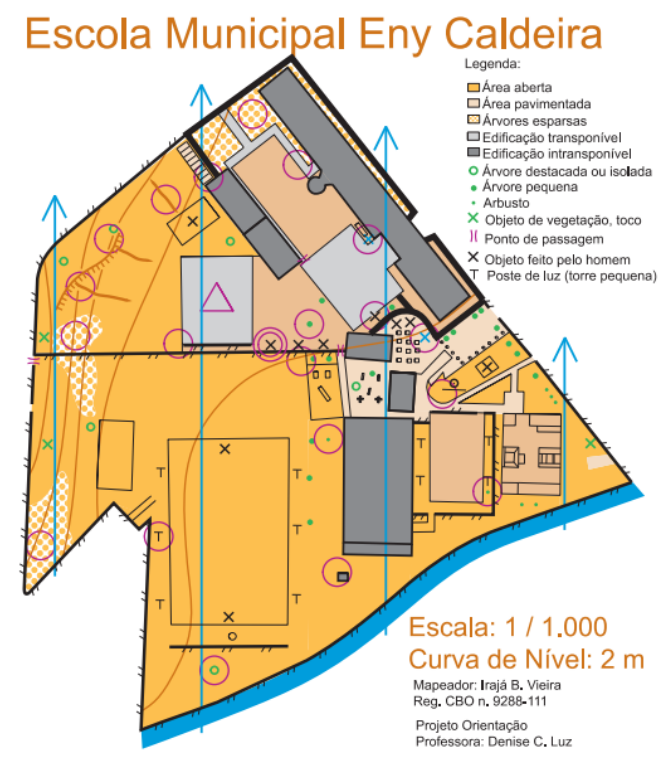

Figura 4. Mapa da Escola Municipal Eny Caldeira. Fonte: Os autores.

Entendemos que o processo de avaliação por observação permite detectar informações relevantes tanto do observador (professor que propõe a prática) quando do avaliado (estudante - executor). É possível assim identificar e propor correções, que não necessariamente precisam estar registradas de forma escrita ou através de desenhos, mas sim no comportamento, atitudes e falas.

A sequência pedagógica básica foi construída a partir da experiência prévia da professora com estudantes do ensino fundamental anos finais, efetuando modificações necessárias, observadas anteriormente, a fim de adaptar as propostas para séries iniciais do ensino fundamental. Para concretizar essa proposta, foi necessária a utilização de recursos materiais e equipamentos, como: computador e impressora, mapas de orientação, prismas de papelão, picotadores, cartão controle e jogos produzidos com material alternativo. Foram utilizados recursos humanos e materiais da unidade escolar para confecção dos jogos, mapas e prismas. Destaca-se que houve a colaboração de um sargento da aeronáutica de Curitiba, experiente mapeador na confecção dos mapas.

\section{RESULTADOS E DISCUSSÃO}

A construção de uma sequência pedagógica demanda tempo de aprendizado do docente, confecção de materiais e construção coletiva que deve ser encampada pelos colegas da escola, incluindo gestoras e pedagogas. Desse modo, é imprescindível retomar a importância da formação continuada para que os professores possam oferecer conteúdo lúdicos e que despertem o interesse e estimulem o envolvimento dos estudantes.

A pesquisadora avalia os resultados da experiência como sendo uma prática exitosa e de fácil aplicação no ambiente escolar, especialmente pela facilidade da estrutura organizada e os conhecimentos trabalhados, aqui sequenciados e aplicados com simples progressão. Os materiais utilizados eram de fácil construção e prática utilização. Destacamos que o aprendizado dos estudantes se deu na ampliação de seus conhecimentos das PCA de forma lúdica, demonstrando autonomia e a clara compreensão na execução das atividades propostas. Os estudantes expressaram outro olhar sobre o ambiente escolar nas rodas de conversa, e apresentaram maior apropriação do espaço, bem como a relação importante desta prática com os ambientes naturais.

A sequência pedagógica foi adequada para a idade, por partir de conhecimentos e exemplificações simples para ações mais complexas, pelos jogos propostos e as conversas em grupos serem explicativas e esclarecedoras, e ainda os primeiros contatos com a prática partirem de um pequeno grupo trabalhando coletivamente e posteriormente a prática ser individual e com autonomia do estudante. Assim os jogos (apresentados na organização e desenvolvimento da proposta) demonstraram poder despertar aprendizados: cognitivo (noções claras de espaço, tempo, direcionamentos, cronometragem, dentre outros), motores (ações básicas estimulantes de correr, saltar, andar) e sociais (cooperação, respeito, responsabilidade, autonomia), trazendo proximidade e interação do aprendizado da Orientação de forma lúdica, ideal para a idade escolar.

Entendemos que a finalidade de uma sequência pedagógica é organizar propostas de ensino-aprendizagem, do simples ao complexo, porém não é "engessada" podendo acontecer interferências e adaptações para conclusão, isso exige reflexão e ação constante do professor, o qual o perfil profissional deve ser de um sujeito reflexivo, crítico, autônomo, pesquisador e aberto ao trabalho colaborativo, comprometido com sua atualização constante (ALARCÃO, 2007; FONTANA; FÁVARO, 2013).

A Orientação se mostra possível na interação e transposição didática entre teoria e prática, proporcionando ao estudante benefícios diversos para o desenvolvimento de um ser humano integral (biopsicossocial).

\section{CONCLUSÃO}

A Orientação é pouco aplicado no ambiente escolar, pois os professores de Educação Física ainda sentem a sua falta no processo formativo e têm certo receio em aplicá-lo. Nesse sentido, observa-se a necessidade de busca pela contínua atualização e saberes docentes, assim como a abertura para inovação de novos temas, experiências e discussões, na construção de uma trajetória permanente, refletindo sobre sua prática docente e 
as possibilidades de ampliá-la, transformá-la e ressignificá-la. Sabemos das dificuldades encontradas neste caminho, porém compartilhar experiências como essa coloca-se como uma estratégia de parceria promissora na ampliação do conhecimento dessa prática.

A sequência pedagógica mostrou-se adequada como proposta inicial, podendo ser ampliado o número de aulas, conforme a necessidade e interesse dos estudantes, do professor e da unidade escolar. A Orientação desenvolvida no ambiente escolar é uma ferramenta pedagógica que facilita o processo de aprendizagem, pois pode (deve) ser desenvolvido em conjunto com outras áreas do conhecimento, além de poder ser inserido em momentos especiais da escola com a participação das famílias. Trata-se de uma atividade motivadora, desafiadora e traz o espírito de competição associada a uma prática em meio a ambientes urbanos e nas florestas (parques e praças).

Visto que os estudantes demonstraram empolgação pela prática, colaboração nos questionamentos, e entendimento sobre regras simples, é possível desenvolver essa sequência e replicá-la em outras escolas ou espaços de lazer. Reconhece-se, dessa forma, a Orientação como grande oportunidade complementar de outras unidades temáticas como o Esporte já inseridos no currículo da Educação Física. Destacamos entre os pontos positivos da sequência pedagógica: a superação de práticas tradicionais; a possibilidade de trabalhar em grupos, trios, duplas e individualmente com os estudantes; a exploração de uma prática inovadora no ambiente escolar e inserção de uma possibilidade de atividade física regular nos momentos de lazer.

As limitações deste relato se dão na parte avaliativa onde não foi possível contribuir com fotos das práticas na unidade escolar, por se tratar de imagens dos estudantes o qual a Secretaria Municipal da Educação não permite exposições, além do ambiente escolar, isto se resolveria com termos de consentimento e assentimento livre esclarecido enviados anteriormente, o que não aconteceu. Também não relatamos as falas dos estudantes por não se tratar naquele momento de uma pesquisa, nossa intenção na época foi observar como dito anteriormente as atitudes e expressões dos estudantes na execução das práticas corporais.

Frente a estas considerações, cabe ressaltar que a Orientação é um tesouro pedagógico que precisa ser explorado, mapeado e adaptado a cada realidade escolar, com a qual se depara e vivencia diferentes realidades e processos formativos.

\section{REFERÊNCIAS}

ALARCÃO, I. Professores reflexivos em uma escola reflexiva. 5. ed. São Paulo: Cortez, 2007.

BRASIL. Ministério da Educação. Base Nacional Comum Curricular (BNCC) Brasília: MEC, 2018. Disponível em: <http//basenacionalcomum.mec.gov. br/imagens/BNCC EI EF 110518 versaofinal site.pdf>. Acessado em: 26 de maio de 2021.

CARVALHO, J. C. Jogos de corrida de orientação para escolas. São Paulo: Yolbook, 2020.

CÁSSARO, E. R. Atividades de aventura nos anos iniciais do ensino fundamental: possibilidades e desafios a partir da BNCC. 2019. $160 \mathrm{f}$. Dissertação (Mestrado em Educação) - Universidade Estadual do Oeste do Paraná, Cascavel, 2019.

CORRÊA, L. V. D. O. M.; BADARÓ, L. F.; de SOUZA, J.; PIMENTEL, G. G. A. Práticas corporais de aventura e biografias de movimento na educação física escolar. Humanidades \& Inovação, Palmas, v. 7, n. 10, 253-65, 2020.

CURITIBA. Prefeitura Municipal. Secretaria Municipal da educação. Currículo do Ensino Fundamental: Educação Física. Curitiba, 2020.

DAOLIO, J. Educação física e o conceito de cultura. 2. ed. Campinas: Autores Associados, 2007

FONTANA, M. J.; FÁVERO, A. A. Professor reflexivo: uma integração entre teoria e prática. Revista de Educação do IDEAU, Rio de Janeiro, v. 8, n. 1, p. 1-14, 2013

FRANCO, L. C. P.; CAVASINI, R.; DARIDO, S. C. Práticas corporais de aventura. In: GONZALEZ, F. J.; DARIDO, S. C.; OLIVEIRA, A. A. B. (Orgs.). Lutas, capoeira e práticas corporais de aventura. v. 4. Maringá: Eduem, 2017. p. 101-36.

INÁCIO, H. L. D.; CAUPER, D. A. C.; SILVA, L. A. P.; MORAIS, G. G. Práticas corporais de aventura na escola: possibilidades e desafios - reflexões para além da Base Nacional Comum Curricular. Motrivivência, Florianópolis, v. 28, n. 48, p. 168-87, 2016.

IOF. International Orienteering Federation. About Orienteering. Disponível em: <https://orienteering.sport/orienteering/>. Acessado em: 26 de maio de 2021.

RODRIGUES, H. A.; DARIDO, S. C. A técnica esportiva em aulas de educação física: um olhar sobre as tendências socioculturais. Movimento, Porto Alegre, v. 14, p. 135-54, 2008.

SCOPEL, A. J. S. G.; FERNANDES, A. V.; RETAMAL, F. C.; PIMENTEL, G. G. A.; NODA, L. M., SANTOS, S. Atividades físicas alternativas: práticas corporais de aventura. Curitiba: Intersaberes, 2020.

SILVA, C. C. Práticas corporais de aventura nos anos iniciais: a organização e a sistematização curricular nas aulas de Educação Física. 2020. 180f. Dissertação (Mestrado em Educação Física) - Universidade Federal do Rio Grande do Norte, Natal, 2020.

SOUSA, D. Q. O.; ARAUJO A. C.; SANTOS A. P. Esporte orientação: relato de experiência pedagógica no ensino médio. Cadernos de Formação RBCE, Natal, v. 6, n. 2, p. 88-100, 2016.

\section{AGRADECIMENTOS}

Gostaríamos de expressar nossa gratidão a todos os estudantes do 5ㅇa ano (quinto ano) da Escola Municipal Eny Caldeira em Curitiba, do ano letivo de 2019, que participaram desta atividade, e ainda estender os agradecimentos a professora de Educação Física Lorena de Fátima Nadolny, responsável pela turma, bem como toda equipe pedagógica e diretiva da unidade e ao sargento Irajá B. Vieira pela produção do mapa da unidade escolar.

Agradecemos também ao Grupo de Estudos e Pesquisa em Educação, Educação Física e Políticas Educacionais (GEEFE) da Universidade Estadual de Maringá (UEM-PR).

\section{CONFLITO DE INTERESSE}

Os autores do estudo declaram não haver conflito de interesses.

\section{FINANCIAMENTO}

Não houve qualquer tipo de apoio financeiro ou financiamento para execução deste projeto.

\section{ORCID E E-MAIL DOS AUTORES}

Denise Correa Luz (Autor Correspondente)

ORCID: 0000-0002-9434-0115.

E-mail: denise_cluz@hotmail.com

Amauri Aparecido Bássoli Oliveira

ORCID: 0000-0002-2566-1476.

E-mail: amauribassoli@gmail.com 